\title{
Associations of Symptomatic or Asymptomatic Peripheral Arterial Disease with All-Cause and Cardiovascular Mortality after 3 Years Follow Up: The China Ankle-Brachial Index Cohort Study
}

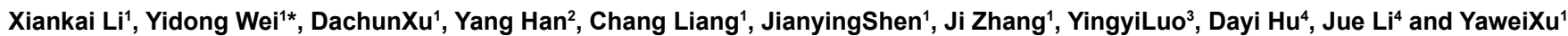

${ }^{1}$ The Department of Cardiology, Shanghai Tenth People's Hospital, Tongji University School of Medicine, Shanghai, 200072, China

${ }^{2}$ Shanghai East Hospital, Shanghai, 200120, China

${ }^{3}$ Shanghai Institute of Health Sciences, No.279, Zhouzhu Highway, Nanhui, Shanghai, 201318, China

${ }^{4}$ Tongji University School of Medicine, 1239 Siping Road, Shanghai, 200092, China

\begin{abstract}
Objective: This study aim to investigate all cause and cardiovascular mortality in Chinese in patients with symptomatic or asymptomatic Peripheral Arterial Disease (PAD) in comparison to those without PAD.
\end{abstract}

Methods: All the subjects were inpatients at high risk of atherosclerosis and consecutively enrolled from July to November, 2004. A total of 3210 were followed up until an end-point was reached or until February 2008. The mean follow-up time was $38 \pm 2$ months.

Results: Compared with non-PAD, PAD patients had significantly higher frequency of coronary artery disease, hypertension, diabetes mellitus, dyslipidemia, stroke or smoking (all $P<0.01$ ). The all cause mortality and cardiovascular mortality in patients with PAD were $25.5 \%$ and $15.6 \%$, respectively. Those with symptomatic and asymptomatic PAD had a statistically significant higher all cause and cardiovascular mortality compared to those without $\mathrm{PAD}(P<0.01)$. The symptomatic PAD patients were 1.834 times $(95 \% \mathrm{Cl}: 1.225-2.746)$ as likely to die as those without PAD, and 1.650 times (95\% Cl: 1.303-2.088) in asymptomatic PAD patients after adjusting for other factors. Those with symptomatic or asymptomatic PAD had more than twice as likely to die of cardiovascular disease as those without PAD (RR: 2.243, 95\% Cl: 1.363-3.691 and RR: 2.100, 95\% Cl: 1.561-2.824, respectively).

Conclusion: In comparison to non-PAD patients, those with PAD were associated with a higher all cause and cardiovascular mortality whether or not PAD is symptomatic. $A B I$ as a marker of atherosclerosis should be routinely done to evaluate PAD in elder patients in China.

Keywords: Peripheral Arterial Disease (PAD); All-cause mortality; Cardiovascular mortality; Ankle Brachial Index (ABI)

\section{Introduction}

Peripheral Arterial Disease (PAD), caused by atherosclerotic occlusion in the arteries of the legs, is an important manifestation of systemic atherosclerosis. The prevalence of PAD is different from different reports [1-6], the age-adjusted prevalence of PAD is approximately $12 \%$ [7].Many trials have shown PAD was associated with considerable general and cardiovascular morbidity and mortality. Our previous study showed a PAD prevalence of $25 \%$ in patients with coronary artery disease [8]. One US study estimated a prevalence of more than 5 million adults. Patients with critical PAD face an annual mortality rate of $25 \%$, which is overwhelmingly due to myocardial infarction and ischemic stroke [9]. However, only few patients present typical intermittent claudication which can be diagnosed PAD. Most of the patients may be under diagnosed due to atypical symptoms. But trials showed the risk of death is high whether or not PAD is symptomatic [10].The early diagnosis of PAD remains as important step to reduce death risk. Ankle-brachial index (ABI), a ratio of ankle systolic blood pressure to brachial systolic pressure, is widely used in clinical practice to assess the potency of the lower arterial system and to screen for PAD. The ABI threshold of 0.9 has a sensitivity of $95 \%$ and a specificity of $100 \%$ compared with angiography [11].

In 2004, our team firstly began to investigate the baseline characters of Chinese PAD patients and reported the prevalence and treatment of those patients. Those patients were followed up to 3 years to evaluate the relationship between mortality and symptomatic or asymptomatic PAD. This paper is prompted to report the relationship between symptomatic PAD, asymptomatic PAD and mortality in Chinese population.

\section{Methods}

\section{Study subjects}

This is the first cohort study focused on PAD in Chinese population. The ABI Cohort Study was designed in 2004 to investigate the risk factors of PAD in Chinese population, and the relationship between mortality and symptomatic or asymptomatic PAD. All the subjects were hospitalized patients aged over 35 years with 2or more cardiovascular (CV) risk factors and consecutively enrolled from eight university hospitals in Shanghai and Beijing from July to November, 2004. CV risk factors included smoking, Diabetes Mellitus (DM), hypertension and dyslipidemia. Exclusion criteria include severe heart failure, liver failure, renal failure or cancer. Finally, a population of 3732 , aged $\geq 35$ years, including 1979 men and 1753 women who had

*Corresponding author: Yidong Wei, The Department of Cardiology, Shanghai Tenth People's Hospital, Tongji University School of Medicine, Shanghai, 200072 China, Tel:+86-021-66306920; E-mail: camelheart@163.com

Received July 26, 2013; Accepted August 22, 2013; Published August 24, 2013

Citation: Li X, Wei Y, Xu D, Han Y, Liang C, et al. (2013) Associations of Symptomatic or Asymptomatic Peripheral Arterial Disease with All-Cause and Cardiovascular Mortality after 3 Years Follow Up: The China Ankle-Brachial Index Cohort Study. J Hypertens 2: 124. doi:10.4172/2167-1095.1000124

Copyright: ( $2013 \mathrm{Li} \mathrm{X}$, et al. This is an open-access article distributed under the terms of the Creative Commons Attribution License, which permits unrestricted use, distribution, and reproduction in any medium, provided the original author and source are credited. 
Citation: Li X, Wei Y, Xu D, Han Y, Liang C, et al. (2013) Associations of Symptomatic or Asymptomatic Peripheral Arterial Disease with All-Cause and Cardiovascular Mortality after 3 Years Follow Up: The China Ankle-Brachial Index Cohort Study. J Hypertens 2: 124. doi:10.4172/21671095.1000124

Page 2 of 6

complete baseline data were entered the cohort. They were followed up until an end-point (death) was reached or until February 2008. This study was approved by the ethics committee of Tongji University and informed consent was obtained from the participants.

\section{Definitions of cardiovascular risk factors: Smoking, DM, hypertension and dyslipidemia}

Smoking refers to the participants who reported smoking cigarettes or had smoked other tobacco products at leastonce a day for 1 year or more [12]; Hypertension was defined as systolic blood pressure $\geq 140$ $\mathrm{mmHg}$, and/or diastolic blood pressure $\geq 90 \mathrm{mmHg}$,and/or current antihypertensive medications[13]; DM was defined as: (1) fasting plasma glucose concentration $>7.0 \mathrm{mmol} / \mathrm{L}$ in the absence of treatment; (2) fasting plasma glucose concentration $\geq 11.0 \mathrm{mmol} / \mathrm{L}, 2 \mathrm{~h}$ after a 75-g oral glucose load; or (3) current treatment with hypoglycemic medications [14]; According to the Chinese guideline, dyslipidemia was defined as total cholesterol (TC) $\geq 5.2 \mathrm{mmol} / \mathrm{L}$, and/or HDL-C $\leq 0.9 \mathrm{mmol} / \mathrm{L}$, and/or LDL-C $\geq 3.12 \mathrm{mmol} / \mathrm{L}$, and/or triglycerides(TG) $\geq 1.69 \mathrm{mmol} / \mathrm{L}$, or undergoing current lipid-lowering treatment.

\section{ABI measurement}

Doppler ultrasound (Nicolet Vascular, Elite 100R, USA) was used to measure systolic pressure on bilateral brachial, position tibial and dorsal pedal arteries after subjects at least 5-min rest in the supine position. The Doppler probe was used at a frequency of $5 \mathrm{MHz}$. The left or right $\mathrm{ABI}$ is the ratio of the pressure on the left or right dorsal or posterior tibial arteries to the higher brachial pressure. An ABI $\leq 0.9$ in either leg was considered as evidence of PAD [15].

\section{Diagnosis and classification of PAD}

The diagnosis of PAD was assessed by ABI measurements and the $\mathrm{ABI} \leq 0.9$ was used to diagnose PAD. Symptomatic PAD was defined as those whose $\mathrm{ABI} \leq 0.9$ and with a typical intermittent claudication; Asymptomatic $\mathrm{PAD}$ was those whose $\mathrm{ABI} \leq 0.9$ but without a typical intermittent claudication; Non-PAD was those with $0.9<\mathrm{ABI}<1.40$.

\section{Identification of all-cause and cardiovascular death}

Death was identified by hospitals' records or by contacting with the participants' families. Further causes of death were investigated by reviewing medical record and informant interviews. The CVD mortality was estimated according to the International Classification of Diseases 10 (ICD-10). All materials were reviewed independently by a physician of ABI cohort study to confirm the cause of death. The death assessment was blinded to $\mathrm{ABI}$ value.

\section{Statistical analysis}

Continuous variables, such as age, SBP, DBP, plasma glucose, TC, TG, HDL-C, and LDL-C were presented as mean \pm SD. Categorical variables were expressed as percentage. All the participants were classified into symptomatic PAD, asymptomatic PAD or Non-PAD group. Independent-samples ANVOA and the Chi-square test were used to compare continuous and categorical differences at baseline, respectively. Kaplan-Meier model was employed to calculate the cumulative mortality rate from all-cause and cardiovascular disease among the three groups. Cox regression model was used to estimate the independent association between PAD and all-cause and cardiovascular mortality compared with Non-PAD, after adjusting for gender, age, SBP, smoking, DM, dyslipidemia, hypertension, CAD, stroke. A $p$-value of $<0.05$ was considered significant. All analyses were performed with SPSS (Statistics Package for Social Science) version 13.0.

\section{Results}

A total of 3732 participants with available baseline data were enrolled in the cohort. Of these, 969 participants (26.0\%) were diagnosed as PAD by ABI. There were 193 patients with symptomatic PAD, 776 were asymptomatic PAD patients and 2763 innon-PAD group.

After a mean follow-up time of $38 \pm 2$ months, 522 of all the subjects (3732) were lost during the follow-up because of the changes of telephone number or family address; the rate of lost to follow-up was $14 \%$. Among those missing subjects, 35 of them were in symptomatic $\mathrm{PAD}$ group, 115 in asymptomatic PAD group, and 372 in non-PAD. After careful calculation, the missing subjects did not significantly affect the major results of this study $(P=0.147$, Table 1$)$. There were 3210 subjects with complete baseline and follow-up data after 3 years follow-up.

The baseline characters of all the subjects were shown in Table 2 . The patients with PAD were older than those without PAD (72 \pm 9 or $72 \pm 10$ vs. $65 \pm 11, P<0.001)$. Compared with non-PAD, PAD patients with or without symptom had significantly higher frequency of CAD, hypertension, DM, dyslipidemia, stroke (all $P<0.001$ ) and smoking $(P<0.01)$.

Table 3 and figure 1 demonstrated the all cause and cardiovascular mortalities among the three groups after 3 years follow-up. Among the 209 PAD patients who died, $43.3 \%$ of PAD patients died of coronary artery disease, $13.6 \%$ for stroke, and $43.1 \%$ patients died of other causes. The all cause mortality and cardiovascular mortality in patients with PAD were $25.5 \%$ and $15.6 \%$, respectively. The symptomatic PAD group had a significant highest all cause and cardiovascular mortalities

\begin{tabular}{|l|l|l|l|l|}
\hline & $\begin{array}{l}\text { Participants with } \\
\text { follow-up (n=3210) }\end{array}$ & $\begin{array}{l}\text { Missing } \\
\text { participants }(\mathbf{n}=\mathbf{5 2 2})\end{array}$ & $\begin{array}{l}\text { Total } \\
\mathbf{( n = 3 7 3 2})\end{array}$ & $\boldsymbol{P}$ value \\
\hline $\begin{array}{l}\text { Symptomatic } \\
\text { PAD (n/\%) }\end{array}$ & $158 / 4.9$ & $35 / 6.7$ & $193 / 5.2$ & \\
\cline { 1 - 3 } & $661 / 20.6$ & $115 / 22.0$ & $776 / 20.8$ & .147 \\
\hline $\begin{array}{l}\text { Psy (n/\%) } \\
\text { Non-PAD (n/\%) }\end{array}$ & $2391 / 74.5$ & $372 / 71.3$ & $2763 / 74.0$ & \\
\hline
\end{tabular}

Table 1: Comparison between follow-up and missing participants.

\begin{tabular}{|c|c|c|c|c|}
\hline Baseline characters & $\begin{array}{l}\text { Symptomatic } \\
\text { PAD }(n=193)\end{array}$ & $\begin{array}{l}\text { Asymptomatic } \\
\text { PAD }(n=776)\end{array}$ & $\begin{array}{l}\text { Non-PAD } \\
(n=2763)\end{array}$ & $P$ value \\
\hline Age (years) & $72 \pm 9$ & $72 \pm 10$ & $65 \pm 11$ & $<0.001$ \\
\hline Gender (male, \%) & 52.3 & 48.5 & 54.4 & $<0.05$ \\
\hline CAD (\%) & 64.8 & 60.6 & 52.3 & $<0.001$ \\
\hline Hypertension (\%) & 87.6 & 77.7 & 70.4 & $<0.001$ \\
\hline $\mathrm{SBP}(\mathrm{mmHg})$ & $146 \pm 26$ & $142 \pm 24$ & $139 \pm 23$ & $<0.001$ \\
\hline $\mathrm{DBP}(\mathrm{mmHg})$ & $80 \pm 14$ & $81 \pm 13$ & $81 \pm 13$ & $>0.05$ \\
\hline DM (\%) & 60.1 & 46.4 & 35.5 & $<0.001$ \\
\hline $\mathrm{PG}(\mathrm{mmol} / \mathrm{L})$ & $6.9 \pm 3.0$ & $6.7 \pm 2.0$ & $6.4 \pm 2.8$ & $<0.05$ \\
\hline Dyslipidemia (\%) & 57.9 & 43.2 & 41.6 & $<0.001$ \\
\hline $\mathrm{TC}(\mathrm{mmol} / \mathrm{L})$ & $4.7 \pm 1.2$ & $4.7 \pm 1.2$ & $4.6 \pm 1.1$ & $>0.05$ \\
\hline TG (mmol/L) & $1.7 \pm 1.0$ & $1.8 \pm 1.5$ & $1.7 \pm 1.1$ & $>0.05$ \\
\hline LDL-C (mmol/L) & $2.8 \pm 0.9$ & $2.7 \pm 0.9$ & $2.8 \pm 1.5$ & $>0.05$ \\
\hline HDL-C (mmol/L) & $1.1 \pm 0.3$ & $1.2 \pm 0.4$ & $1.2 \pm 0.4$ & $<0.05$ \\
\hline Stroke (\%) & 61.7 & 51.9 & 38.3 & $<0.001$ \\
\hline Smoking (\%) & 48.7 & 40.6 & 38.0 & $<0.01$ \\
\hline
\end{tabular}

CAD: Coronary Artery Disease; SBP: Systolic Blood Pressure; DBP: Diastolic Blood Pressure; PG: Plasma Glucose; DM: Diabetes Mellitus; TC: Total Cholesterol; TG: Triglycerides; LDL-C: Low Density Lipoprotein Cholesterol; HDL-C: High Density Lipoprotein Cholesterol

Table 2: Baseline characters of all the participants. 
Citation: Li X, Wei Y, Xu D, Han Y, Liang C, et al. (2013) Associations of Symptomatic or Asymptomatic Peripheral Arterial Disease with All-Cause and Cardiovascular Mortality after 3 Years Follow Up: The China Ankle-Brachial Index Cohort Study. J Hypertens 2: 124. doi:10.4172/21671095.1000124

Page 3 of 6

\begin{tabular}{|l|l|l|l|l|l|}
\hline $\begin{array}{l}\text { 3-year } \\
\text { Mortality } \\
\mathbf{( n / \% )}\end{array}$ & $\begin{array}{l}\text { Symptomatic } \\
\text { PAD }(\mathbf{n = 1 5 8})\end{array}$ & $\begin{array}{l}\text { Asymptomatic } \\
\text { PAD }(\mathbf{n}=\mathbf{6 6 1})\end{array}$ & $\begin{array}{l}\text { Non-PAD } \\
\mathbf{( n = 2 3 9 1 )}\end{array}$ & $\begin{array}{l}\text { Total } \\
(\mathbf{n = 3 2 1 0})\end{array}$ & P value \\
\hline $\begin{array}{l}\text { All cause } \\
\text { Mortality }\end{array}$ & $43 / 27.2$ & $166 / 25.1$ & $294 / 12.3$ & $503 / 15.7$ & $<.001$ \\
\hline $\begin{array}{l}\text { Cardiovascular } \\
\text { mortality }\end{array}$ & $28 / 17.7$ & $100 / 15.1$ & $158 / 6.6$ & $286 / 8.9$ & $<.001$ \\
\hline
\end{tabular}

Table 3: Three year all cause and cardiovascular mortality among the three groups.

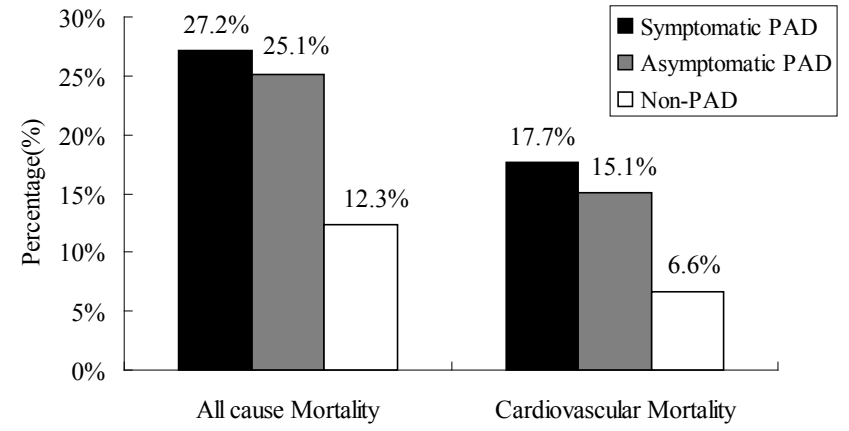

Figure 1: Mortality among the three groups.

$(P<0.001)$ among the three groups. The mortality was still significant higher in asymptomatic PAD group than Non-PAD group $(P<0.001)$.

Figure $2 \mathrm{~A}$ and $2 \mathrm{~B}$ illustrated the survival distribution of the three groups for all-cause and cardiovascular mortality, respectively. The cumulate survival rate in patients with symptomatic or asymptomatic PAD was significantly lower than those without PAD (log-rank: $P<0.001)$.

Figure $3 \mathrm{~A}$ and $3 \mathrm{~B}$ showed the adjusted relative risk (RR) of all cause and cardiovascular mortality in the three groups. The symptomatic PAD patients were 1.834 times (95\% CI: $1.225-2.746$ ) as likely to die as those without PAD, and 1.650times (95\% CI: 1.303-2.088) in asymptomatic PAD patients after adjusting for gender, age, SBP, smoking, DM, dyslipidemia, hypertension, CAD, stroke. Those with symptomatic or asymptomatic PAD had more than twice as likely to die of cardiovascular disease as those without PAD (RR: 2.243, 95\% CI: $1.363-3.691$ and RR: $2.100,95 \%$ CI: 1.561-2.824, respectively) after adjusting for other factors.

Table 4 demonstrated the comparison of cardiovascular mortality in three groups, patients with CAD, hypertension, DM, stroke, or diuretic usage increase the cardiovascular mortality by univariate analysis (all $P<0.05$ ). Patients who take statin, ACEI, or antiplatelet agents decrease cardiovascular mortality. After adjusting for gender, age, CAD, hypertension, DM, dyslipidemia, stroke, smoking, statin, ACEI, ARB, antiplatelet agent, beta blocker, CCB, diuretics, and hypoglycemic agent, the relative risks (95\% CI) for cardiovascular mortality were showed in Figure 4. Statin (RR: 0.641, 95\%CI: $0.497-$ 0.851), ACEI (RR: 0.689, 95\%CI: 0.479-0.989) and antiplatelet agents (RR: 0.747, 95\%CI: 0.594-0.901) were independent protective factors again cardiovascular mortality, while DM (RR: 1.700, 95\%CI: 1.040 2.799) and diuretics (RR: $2.168,95 \% \mathrm{CI}$ : 1.551-3.030) were independent risk factors for cardiovascular mortality.

\section{Discussion}

Atherosclerosis is a systematic disease which is the leading cause of death and waste of health resources in adults worldwide. Recently, physician tried to find a predictor to identify atherosclerotic disease earlier. Epidemiological and clinical trials have proved PAD is widely accepted as an indicator for generalized atherosclerosis. But PAD is quite often asymptomatic in older adults. However, trials showed both symptomatic and asymptomatic patients with PAD have an increased mortality compared to those without PAD [16]. Many trials have also shown $\mathrm{ABI}$ could be used as a marker of PAD and predict cardiovascular or overall mortality. However, there was no epidemiological data focused on Chinese population.

This is the first large-scale ABI cohort study focused on Chinese PAD patients in China. A prevalence of $26 \%$ of $\mathrm{PAD}$ in high risk patients was found at baseline in China. Stoffers HE reported up to three-quarters of patients with PAD were asymptomatic [17], but our research showed four-fifths of PAD patients without typical symptom. That means most of the PAD diagnosis will be missed only by typical intermittent claudication.

Survival Functions

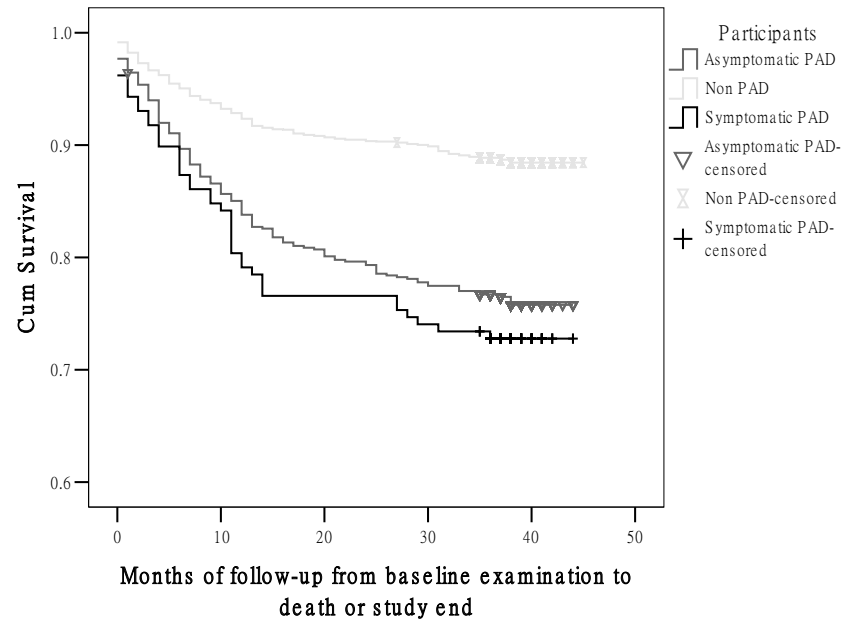

Figure 2A: Univariate Kaplan-Meier curves for subjects among the three groups for all-cause mortality after 3 years follow-up.

Survival Functions

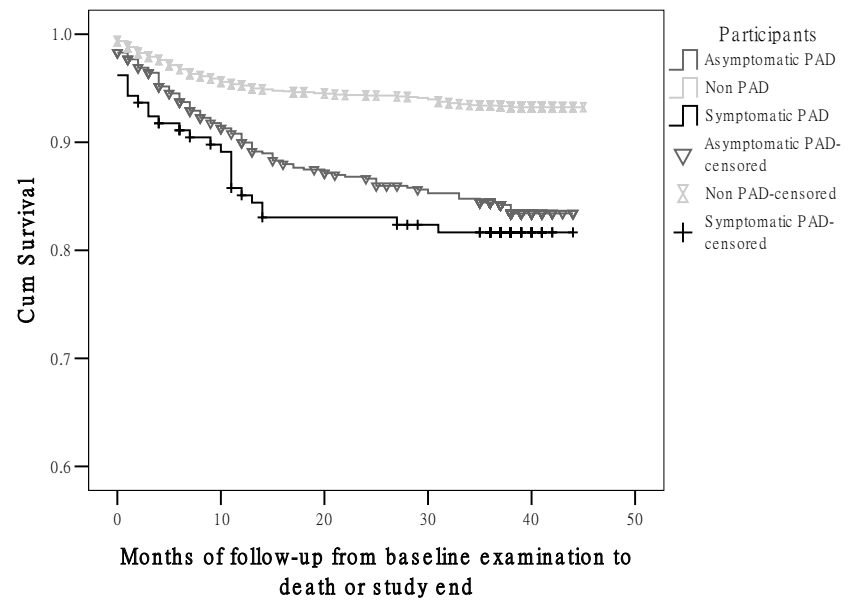

Figure 2B: Univariate Kaplan-Meier curves for subjects among the three groups for cardiovascular mortality after 3 years follow-up. 
Citation: Li X, Wei Y, Xu D, Han Y, Liang C, et al. (2013) Associations of Symptomatic or Asymptomatic Peripheral Arterial Disease with All-Cause and Cardiovascular Mortality after 3 Years Follow Up: The China Ankle-Brachial Index Cohort Study. J Hypertens 2: 124. doi:10.4172/21671095.1000124

Page 4 of 6

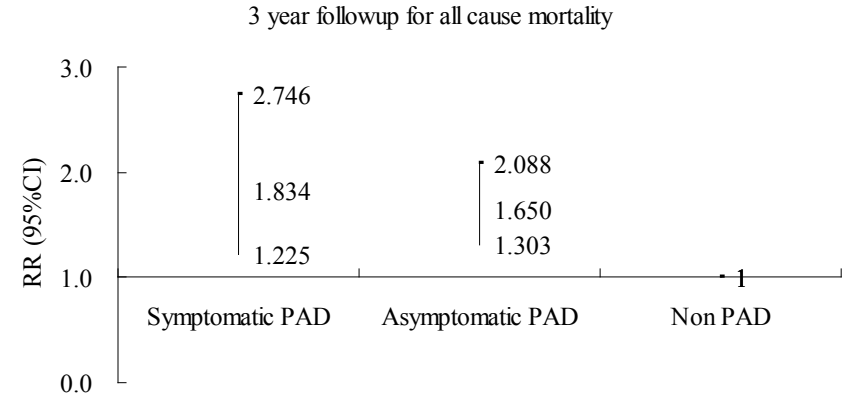

Figure 3A: Multivariate-adjusted relative risks $(95 \% \mathrm{Cl})$ of all cause mortality among the 3 groups after 3 years of follow-up.

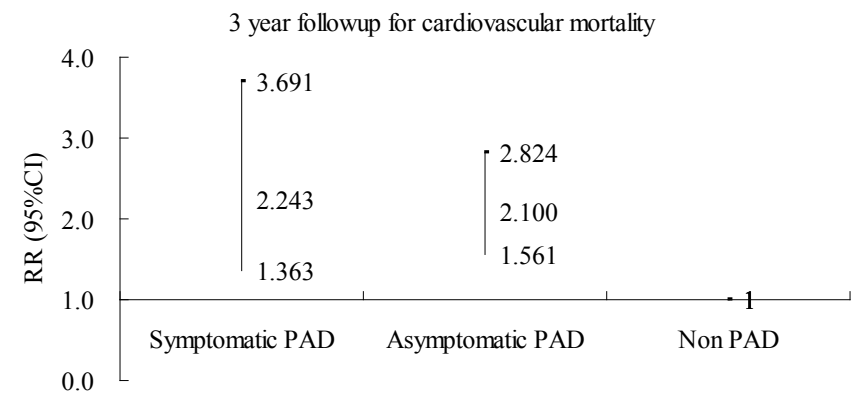

Figure 3B: Multivariate-adjusted relative risks $(95 \% \mathrm{Cl})$ of cardiovascula mortality among the 3 groups after 3 years of follow-up.

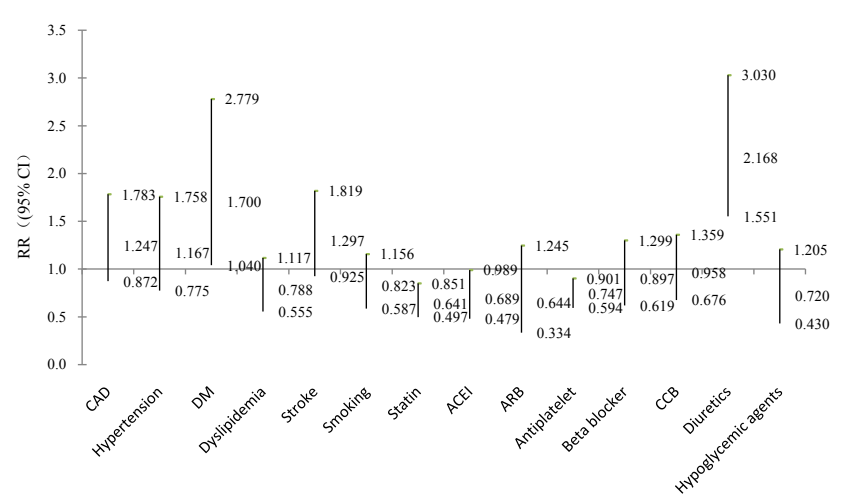

Figure 4: Multivariate-adjusted relative risks $(95 \% \mathrm{Cl})$ for cardiovascular mortality after adjusting for gender, age, CAD, hypertension, DM, dyslipidemia, stroke, smoking, statin, ACEI, ARB, antiplatelet agent, beta blocker, CCB, diuretics, and hypoglycemic agent.

The patients with PAD were older and had a higher frequency of CAD, hypertension, DM, dyslipidemia, stroke and smoking whether PAD was symptomatic or not than those without PAD at baseline, which was similar to Newman's former report [5].

During the 3 years follow-up, there was a significant increase tendency on all cause mortality from non-PAD, asymptomatic PAD to symptomatic PAD; the same to cardiovascular mortality. The all cause mortality was $27.2 \%$ in patients with symptomatic PAD, $25.1 \%$ in patients with asymptomatic PAD, and $12.3 \%$ in patients without $\mathrm{PAD}$ in China. The all cause mortality in patients with PAD was $25.5 \%$.
Diehm C and Get ABI study reported the 3 years all cause mortality was $10.9 \%$ in patients with PAD [18]; our results were much higher than theirs partly because our subjects were inpatients at high risk of atherosclerosis. But all those data highlighted patients with PAD were at very high risk of death, regardless of cause. Diehm C further showed the 5 years all cause mortality was $24.1 \%$ in patients with symptomatic PAD , 19.2\% in patients with asymptomatic PAD, and 9.5\% in patients without PAD. And others reported the estimated five year mortality in patients with PAD was $30 \%[19,20]$.

In the REAL registry in Europe, 11118patients with STEMI undergoing primary PCI was followed up to 3 years. There were 1779 deaths. The cumulative incidence of death was $12.1 \%$ at 1 year and $17.5 \%$ at 3 years [21].There were $2032(18.2 \%)$ patients had a diagnosis of COPD. Overall, 1829 (16.5\%) patients died. COPD was an independent predictor of mortality [22].Compared with the mortality listed above in European population, the mortality of this research was a little bit higher. The reasons may include: (1) According to the ATPIII guideline, $\mathrm{PAD}$ is a $\mathrm{CHD}$ risk equivalent, which has a risk for developing major coronary event (>20\% per 10year), this means PAD patients has a risk of die CVD; (2) In the current research, all the participants were INPATIENTs with at least 2 CHD risk factors; Most of the PAD patients concomitant with $\mathrm{CAD}$, hypertension, DM, dyslipidemia, smoking or prior stroke, which means those PAD patients per se were at very high risk of die of cardiovascular diseases. For example, there were 635 (65.5\%) PAD patients concomitant with CAD only. Among the 209 PAD patients who died, $43.3 \%$ of PAD patients died of coronary artery disease, $13.6 \%$ for stroke, and $43.1 \%$ patients died of other causes. So, the mortality in PAD group was a little bit higher than that of other reports; (3) Another reason for high mortality was that all the inpatients were enrolled from big or high rank hospitals, those hospitals usually have more severe patients than regular hospitals in China. Those patients with more severe or complicated diseases have a higher mortality.

After adjusting for gender, age, smoking, CAD, hypertension, stroke, DM, dyslipidemia for those diseases by Cox regression model, the symptomatic PAD patients were 1.834 times as likely to die as those without PAD, and 1.650 times in asymptomatic PAD patients. The risk of death in patients with symptomatic or asymptomatic PAD was more than 2-fold higher than that of non-PAD. Research from Criqui $\mathrm{MH}$ showed a twofold of the mortality rate among patients with intermittent claudication. Patients with PAD, regardless of symptom, were 3.1 times as likely to die as those without PAD, and 5.9 times to die from cardiovascular disease after 10 years follow up [23]. Diehm C reported that those with symptomatic PAD (HR: 2.66; 95\% CI: 2.25 to 3.15 ) or asymptomatic PAD (HR: $1.81 ; 95 \%$ CI: 1.53 to 2.14 ) had a significantly increased risk to composite outcome in comparison with those without PAD [24]. Although data showed symptomatic PAD patient were at highest risk of death, all those suggested PAD patients were at high risk of death compared with those without PAD, whether or not PAD is symptomatic.

In this study, we showed those with asymptomatic PAD was still at high risk of death. Moreover, our research and other reports proved that a low $\mathrm{ABI}$ is a strong predictor of mortality during the follow-up even in patients with no clinical symptoms of PAD $[25,26]$. A recent meta-analysis also showed measurement of the ABI may improve the accuracy of cardiovascular risk prediction beyond the Framingham risk score which further highlight the importance of ABI [27].

Although PAD is highly prevalent, physician awareness and detection of the disease was low $[8,28]$, perhaps the high rate of 
Citation: Li X, Wei Y, Xu D, Han Y, Liang C, et al. (2013) Associations of Symptomatic or Asymptomatic Peripheral Arterial Disease with All-Cause and Cardiovascular Mortality after 3 Years Follow Up: The China Ankle-Brachial Index Cohort Study. J Hypertens 2: 124. doi:10.4172/21671095.1000124

Page 5 of 6

\begin{tabular}{|c|c|c|c|c|c|c|c|}
\hline \multirow{2}{*}{ Variable } & \multicolumn{2}{|c|}{ Symptomatic PAD (n=158) } & \multicolumn{2}{|c|}{ Asymptomatic PAD (n=661) } & \multicolumn{2}{|c|}{ Non-PAD (n=2391) } & \multirow{2}{*}{$P$ Value * } \\
\hline & Death & None & Death & None & Death & None & \\
\hline CAD & $30(69.8 \%)$ & $75(65.2 \%)$ & $104(62.7 \%)$ & $297(60 \%)$ & $145(49.3 \%)$ & $1137(54.2 \%)$ & 0.003 \\
\hline Hypertension & $39(90.7 \%)$ & $99(86.1 \%)$ & $133(80.1 \%)$ & $385(77.8 \%)$ & $204(69.4 \%)$ & $1494(71.2 \%)$ & 0.002 \\
\hline DM & $27(62.8 \%)$ & $66(57.4 \%)$ & $74(44.6 \%)$ & $224(45.3 \%)$ & $100(34 \%)$ & $740(35.3 \%)$ & 0.001 \\
\hline Dyslipidemia & $12(42.9 \%)$ & $58(61.7 \%)$ & $44(35.5 \%)$ & $180(44.8 \%)$ & $72(29.9 \%)$ & $756(42.4 \%)$ & 0.269 \\
\hline Stroke & $26(60.5 \%)$ & $70(60.9 \%)$ & $90(54.2 \%)$ & $249(50.3 \%)$ & $128(43.5 \%)$ & $791(37.7 \%)$ & 0.023 \\
\hline Smoking & $25(58.1 \%)$ & $53(46.1 \%)$ & $72(43.4 \%)$ & $203(41 \%)$ & $129(43.9 \%)$ & $780(37.2 \%)$ & 0.190 \\
\hline Statin & $18(41.9 \%)$ & $52(45.2 \%)$ & $47(28.3 \%)$ & $209(42.2 \%)$ & $79(26.9 \%)$ & $782(37.4 \%)$ & 0.002 \\
\hline ACEI & $27(52.2 \%)$ & $60(62.8 \%)$ & $71(42.8 \%)$ & $277(56 \%)$ & $122(41.6 \%)$ & $966(46.2 \%)$ & 0.031 \\
\hline ARB & $6(14 \%)$ & $11(9.6 \%)$ & $17(10.2 \%)$ & $41(8.3 \%)$ & $30(10.2 \%)$ & $198(9.5 \%)$ & 0.747 \\
\hline Antiplatelet & $33(76.7 \%)$ & $92(80 \%)$ & $105(63.3 \%)$ & $335(67.7 \%)$ & $154(52.4 \%)$ & $1357(64.9 \%)$ & 0.003 \\
\hline Beta blocker & $20(46.5 \%)$ & $57(49.6 \%)$ & $63(38.0 \%)$ & $198(40 \%)$ & $77(26.2 \%)$ & $811(38.8 \%)$ & 0.003 \\
\hline CCB & $18(41.9 \%)$ & $58(50.4 \%)$ & $63(38 \%)$ & $207(41.8 \%)$ & $83(28.2 \%)$ & $766(36.6 \%)$ & 0.041 \\
\hline Diuretics & $18(41.9 \%)$ & $32(27.8 \%)$ & $80(48.2 \%)$ & $164(33.1 \%)$ & $130(44.2 \%)$ & $473(22.6 \%)$ & 0.036 \\
\hline Hypoglycemic agent & $22(51.2 \%)$ & $57(49.6 \%)$ & $63(38 \%)$ & 183(37\%) & $75(25.5 \%)$ & $615(29.4 \%)$ & 0.001 \\
\hline
\end{tabular}

${ }^{*} P$ value for cardiovascular mortality

Table 4: Comparison of cardiovascular mortality in three groups

asymptomatic disease was the most important reason[17]. ABI was regarded as indictor of mortality for many years, but in the whole strategy of atherosclerosis risk detection, less attention has been paid to the measurement of $\mathrm{ABI}$ and therefore the presence of PAD has been underscored or not recognized [28,29]. Hence, screening for PAD should be performed routinely in all elderly patients and in general population who are at increased risk of atherosclerosis. Evaluation is now required of the potential of incorporating $\mathrm{ABI}$ measurement into atherosclerosis prevention programs. PAD should be aggressively treated just as coronary artery disease [30]. All those measures should be applied to identify PAD in order to reduce mortality.

The possible strategies to identify this high risk population and to reduce the burden of mortality included: (1) we suggest early detection of ABI in PAD high risk population; (2) therapeutic lifestyle changes if PAD was diagnosed; (3) aggressive medical therapy with statin, ACEI, and antiplatelet therapy for secondary prevention. Those comprehensive treatments may help to reduce the burden of mortality.

There are several limitations to our study. Firstly, the duration of follow-up is only 3 years, further study should be done. Secondly, $14 \%$ of the subjects were lost during the follow-up due to the changes of telephone number or family address. If not, we could get more precise results. Thirdly, all the subjects were inpatients at high risk of atherosclerosis; our study cannot represent the general population.

\section{Acknowledgements}

This work was partly supported by the National Natural Science Funds of China (No. 81000113) for Xiankai Li and (No.30800466, No.81270193) for Yidong Wei.

\section{References}

1. Schroll M, Munck O (1981) Estimation of peripheral arteriosclerotic disease by ankle blood pressure measurements in a population study of 60 -year-old men and women. J Chronic Dis 34: 261-269.

2. Meijer WT, Hoes AW, Rutgers D, Bots ML, Hofman A, et al. (1998) Peripheral arterial disease in the elderly: The Rotterdam Study. Arterioscler Thromb Vasc Biol 18: 185-192.

3. Fowkes FG, Housley E, Cawood EH, Macintyre CC, Ruckley CV, et al. (1991) Edinburgh Artery Study: prevalence of asymptomatic and symptomatic peripheral arterial disease in the general population. Int J Epidemiol 20: 384 392

4. Newman AB, Sutton-Tyrrell K, Rutan GH, Locher J, Kuller LH (1991) Lower extremity arterial disease in elderly subjects with systolic hypertension. J Clin Epidemiol 44: 15-20.
5. Newman AB, Siscovick DS, Manolio TA, Polak J, Fried LP, et al. (1993) Anklearm index as a marker of atherosclerosis in the Cardiovascular Health Study. Cardiovascular Heart Study (CHS) Collaborative Research Group. Circulation 88: $837-845$

6. Zheng ZJ, Sharrett AR, Chambless LE, Rosamond WD, Nieto FJ, et al. (1997) Associations of ankle-brachial index with clinical coronary heart disease, stroke and preclinical carotid and popliteal atherosclerosis: the Atherosclerosis Risk in Communities (ARIC) Study. Atherosclerosis 131: 115-125.

7. Criqui MH, Denenberg JO, Langer RD, Fronek A (1997) The epidemiology of peripheral arterial disease: importance of identifying the population at risk. Vasc Med 2: 221-226.

8. Hasimu B, Li J, Nakayama T, Yu J, Yang J, et al. (2006) Ankle brachial index as a marker of atherosclerosis in Chinese patients with high cardiovascular risk. Hypertens Res 29: 23-28.

9. Dormandy J, Heeck L, Vig S (1999) The fate of patients with critical leg ischemia. Semin Vasc Surg 12: 142-147.

10. Leng GC, Lee AJ, Fowkes FG, Whiteman M, Dunbar J, et al. (1996) Incidence, natural history and cardiovascular events in symptomatic and asymptomatic peripheral arterial disease in the general population. Int J Epidemiol 25: 1172 1181.

11. Fowkes FG (1988) The measurement of atherosclerotic peripheral arterial disease in epidemiological surveys. Int J Epidemiol 17: 248-254.

12. WHO (1984) Arterial hypertension report of a WHO expert committee. Geneva

13. [No authors listed] (1999) 1999 World Health Organization-International Society of Hypertension Guidelines for the Management of Hypertension. Guidelines Subcommittee. J Hypertens 17: 151-183.

14. Alberti KG, Zimmet PZ (1998) Definition, diagnosis and classification of diabetes mellitus and its complications. Part 1: diagnosis and classification of diabetes mellitus provisional report of a WHO consultation. Diabet Med 15: 539-553.

15. Hirsch AT, Haskal ZJ, Hertzer NR, Bakal CW, Creager MA, et al. (2006) ACC/ AHA Guidelines for the Management of Patients with Peripheral Arterial Disease (lower extremity, renal, mesenteric, and abdominal aortic): a collaborative report from the American Associations for Vascular Surgery/Society for Vascular Surgery, Society for Cardiovascular Angiography and Interventions, Society for Vascular Medicine and Biology, Society of Interventional Radiology, and the ACC/AHA Task Force on Practice Guidelines (writing committee to develop guidelines for the management of patients with peripheral arterial disease)-summary of recommendations. J Vasc Interv Radiol 17: 1383-1397.

16. Rockson SG, Cooke JP (1998) Peripheral arterial insufficiency: mechanisms natural history, and therapeutic options. Adv Intern Med 43: 253-277.

17. Stoffers HE, Rinkens PE, Kester AD, Kaiser V, Knottnerus JA (1996) The prevalence of asymptomatic and unrecognized peripheral arterial occlusive disease. Int J Epidemiol 25: 282-290. 
Citation: Li X, Wei Y, Xu D, Han Y, Liang C, et al. (2013) Associations of Symptomatic or Asymptomatic Peripheral Arterial Disease with All-Cause and Cardiovascular Mortality after 3 Years Follow Up: The China Ankle-Brachial Index Cohort Study. J Hypertens 2: 124. doi:10.4172/21671095.1000124

18. Diehm C, Lange S, Darius H, Pittrow D, von Stritzky B, et al. (2006) Association of low ankle brachial index with high mortality in primary care. Eur Heart J 27: 1743-1749.

19. Dieter RS, Chu WW, Pacanowski JP Jr, McBride PE, Tanke TE (2002) The significance of lower extremity peripheral arterial disease. Clin Cardiol 25: 3-10.

20. Weitz JI, Byrne J, Clagett GP, Farkouh ME, Porter JM, et al. (1996) Diagnosis and treatment of chronic arterial insufficiency of the lower extremities: a critical review. Circulation 94: 3026-3049.

21. Campo G, Saia F, Guastaroba P, Marchesini J, Varani E, et al. (2011) Prognostic impact of hospital readmissions after primary percutaneous coronary intervention. Arch Intern Med 171: 1948-1949.

22. Campo G, Guastaroba P, Marzocchi A, Santarelli A, Varani E, et al. (2013) Impact of Chronic Obstructive Pulmonary Disease on Long-Term Outcome after ST-segment elevation Myocardial Infarction receiving primary Percutaneous Coronary Intervention. Chest doi: 10.1378/chest.12-2313.

23. Criqui MH, Langer RD, Fronek A, Feigelson HS, Klauber MR, et al. (1992) Mortality over a period of 10 years in patients with peripheral arterial disease. N Engl J Med 326: 381-386.

24. Diehm C, Allenberg JR, Pittrow D, Mahn M, Tepohl G, et al. (2009) Mortality and vascular morbidity in older adults with asymptomatic versus symptomatic peripheral artery disease. Circulation 120: 2053-2061.
25. Leng GC, Fowkes FG, Lee AJ, Dunbar J, Housley E, et al. (1996) Use of ankle brachial pressure index to predict cardiovascular events and death: a cohort study. BMJ 313: 1440-1444.

26. Newman AB, Shemanski L, Manolio TA, Cushman M, Mittelmark M, et al. (1999) Ankle-arm index as a predictor of cardiovascular disease and mortality in the Cardiovascular Health Study. The Cardiovascular Health Study Group. Arterioscler Thromb Vasc Biol 19: 538-545.

27. Ankle Brachial Index Collaboration, Fowkes FG, Murray GD, Butcher I, Heald $\mathrm{CL}$, et al. (2008) Ankle brachial index combined with Framingham Risk Score to predict cardiovascular events and mortality: a meta-analysis. JAMA 300 197-208.

28. Hirsch AT, Criqui MH, Treat-Jacobson D, Regensteiner JG, Creager MA, et al. (2001) Peripheral arterial disease detection, awareness, and treatment in primary care. JAMA 286: 1317-1324.

29. Heidrich H, Wenk R, Hesse P (2004) Frequency of asymptomatic periphera arterial disease in patients entering the department of general and internal medicine of a general-care hospital. Vasa 33: 63-67.

30. Grundy SM, Cleeman JI, Merz CN, Brewer HB Jr, Clark LT, et al. (2004) Implications of recent clinical trials for the National Cholesterol Education Program Adult Treatment Panel III guidelines. Circulation 110: 227-239. 